JIEBAR : Journal of Islamic Education: Basic and Applied Research

Vol. 01, Nomor 01, April 2020

P-ISSN: $x x x x-x x x x$

DOI:

E-ISSN: $x x x x-x x x x$

http://e-journal.stit-islamic-village.ac.id/index.php/JIEBAR

\title{
KESALEHAN SOSIAL MELALUI PENDIDIKAN FILANTROPI ISLAM
}

\author{
Fauzi al-Mubarok \\ Sekolah Tinggi Ilmu Tarbiyah Islamic Village Tangerang \\ Email: fauzialmubarok.stit@gmail.com \\ Ahmad Buchori Muslim \\ Sekolah Tinggi Ilmu Tarbiyah Islamic Village Tangerang \\ Email: ahmadbuchori23@gmail.com
}

Received: 12 Januari 2020.

Published: 7 April 2020.

Accepted: 26 Januari 2020.

\begin{abstract}
The balance between spiritual piety and social righteousness is a religious order of Islam, both the teachings listed in the Qur'an, as well as in the Hadith Rasulullah SAW. And among one of the social piety is to give the philanthropy of Islam, this is as a form of gratitude for the gift of sustenance given by Allah SWT to philanthropists, as well as his sense to fellow Muslims in hopes can Relieve their life burden. The righteous philanthropist will carry out the commandment of God and his apostle with sincerity and full of consciousness that wealth and wealth so as not to continue to spin around the rich man alone, therefore with the Islamic philanthropy of wealth and wealth can Enjoyed the results by Fakir, poor, Dhuafa, orphans, and who are entitled to receive it to improve their welfare in the field of economics, health and education. Spiritual righteousness and social righteousness need to be established early on perhaps through education and teaching conducted in primary and secondary schools. These two forms of righteousness are like two currencies that cannot be separated from each other, so that the righteous are spiritually more grounded and influential in the surrounding environment.
\end{abstract}

Keywords: Philanthropy of Islam, Social Righteousness

\section{ABSTRAK}

Keseimbangan antara kesalehan spiritual dan kesalehan sosial merupakan perintah agama Islam, baik ajaran yang tercantum dalam al-Qur'an, maupun dalam hadits Rasulullah $S A W$. Dan di antara salah satu kesalehan sosial adalah dengan memberikan filantropi Islam, hal ini sebagai wujud rasa syukur atas karunia rezeki yang diberikan Allah SWT kepada filantropis, juga sebagai rasa empatinya kepada sesama umat Islam dengan harapan 
dapat meringankan beban hidup mereka. Filantropis yang saleh akan melaksanakan perintah Allah dan Rasul-Nya dengan penub keikblasan dan penuh kesadaran babwa barta dan kekayaan agar tidak. terus berputar di sekeliling orang kaya saja, maka dari itu dengan filantropi Islam harta dan kekayaan bisa dinikmati hasilnya oleh fakir, miskin, dhuafa, yatim piatu, dan yang berbak menerimanya untuk meningkatkan kesejabteraan mereka di bidang ekonomi, kesehatan dan pendidikan. Kesalehan spiritual dan kesalehan sosial perlu dibentuk sejak dini mungkin melahi pendidikan dan pengajaran yang dilakukan di sekolah dasar dan menengah. Kedua bentuk. kesalehan tersebut seperti dua mata uang yang tidak bisa dipisabkan satu sama lain, sehingga orang yang saleh secara spiritual menjadi lebih membumi dan berpengarub nyata terbadap lingkungan sekitarnya.

\section{Kata Kunci: Filantropi Islam, Kesalehan Sosial}

\section{PENDAHULUAN}

Dewasa ini orang tidak hanya terlibat atau melibatkan diri dalam kegiatan sosial yang sifatnya individual, melainkan mereka ikut serta dalam kegiatan yang bersifat kolektif dan berdimensi sosial. Mereka mulai menyadari perlunya menggabungkan diri dalam kelompok-kelompok filantropi untuk bersamasama menyelesaikan masalah kemiskinan dan meningkatkan kesejahteraan masyarakat baik yang terdapat di sekeliling lingkungan terdekat, maupun masyarakat yang jauh di luar pulau atau di luar negeri (Hilman Latief: 2010).

Semangat untuk pelibatan diri dalam kegiatan-kegiatan sosial kemasyarakatan yang saat ini sebenarnya sudah ada dalam budaya republik Indonesia sejak dahulu kala. Semangat semacam ini dalam budaya masyarakat Indonesia dikenal sebagai semangat "gotong royong" yang pada saat ini mendapatkan sebuah justifikasi sebagai salah satu karakter yang harus diajarkan dan diinternalisasikan kepada seluruh warga negara Indonesia khususnya melalui dunia pendidikan.

Sebagai salah satu unsur utama penumbuhan nilai karakter yang dijelaskan dalam sebuah kebijakan tentang Penguatan Pendidikan Karakter (PPK) yang terintegrasi dengan Gerakan Nasional Revolusi Mental yang menjadi nawacita Presiden Joko Widodo dan Wakil Presiden Jusuf Kalla. Sebagai bentuk upaya dalam membangun dan membekali peserta didik sebagai generasi emas Indonesia Tahun 2045 yang siap menghadapi dinamika perubahan di masa depan. 
Semangat gotong royong yang dalam makna pelibatan seseorang dalam kegiatan sosial dan kepedulian sosial secara sukarela merupakan sebuah ajaran agama Islam yang dapat ditelusuri pada sabda Rosulullah SAW. Sebagaimana dalam hadits Rasulullah SAW:

"Tujuh golongan akan mendapat naungan Allah di hari tidak ada naungan kecuali naungan-Nya: imam yang adil, pemuda yang besar dengan konsisten ibadah kepada Allah, orang yang hatinya terpaut dengan masjid, dua orang yang saling mencintai karena Allah, laki-laki yang diajak berzina dia berkata takut kepada Allah, orang yang merahasiakan sedekahny a bingga tangan kirinya tidak tahu apa yang diinfakkan tangan kanannya, dan orang yang berzikir dalam kesunyian bingga air matanya bercucuran.” (HR. Bukhari).

\section{METODE PENELITIAN}

Penelitian ini merupakan penelitian kepustakaan atau kajian literatur (library research), dengan metode pendekatan tematik sebagai pendekatan dalam pengumpulan dan pembahasan datanya. Sedangkan teknis analisis data yang digunakan adalah analisis isi (content analysis), yaitu teknis penelitian yang digunakan untuk menganalisa makna yang terkandung di dalam data yang dihimpun melalui riset kepustakaan.

\section{PEMBAHASAN}

\section{A. Akar Filantropi Islam}

Dalam kamus bahasa Indonesia philanthropy dibaca filantropi berarti cinta kasih atau kedermawanan kepada sesama (Pusat Bahasa: 2008). Secara konsepsional, filantropi dalam Islam mencakup zakat, infak, sedekah dan wakaf. Semua konsep itu menjadi ajaran Islam yang penting, yang termaktub di dalam kitab suci al-Qur'an dan Hadits Nabi Muhammad SAW. Keempat konsep filantropi tersebut menggabungkan dimensi ibadah, sosial, dan ekonomi sekaligus. Ibadah, karena melaksanakan perintah Allah, dan sosial karena menyantuni kelompok masyarakat yang kurang beruntung (Ahmad Gaus: 2008: 9).

Filantropi memiliki cakupan makna yang luas dari amal (charity). Keduanya sama-sama bersumber pada kebaikan hati dan kasih sayang kepada sesama, tetapi amal cenderung bersifat individual, sporadis, dan pengelolaannya pun bersifat konvensional. Sedangkan filantropi bersifat progresif, gerakannya terencana dengan tujuan yang terukur serta melibatkan 
organisasi, baik pemerintah, perusahaan swasta, maupun prakarsa swadaya masyarakat (Ahmad Gaus: 2008: 4).

Filantropi Islam pada masa Rasulullah SAW tumbuh dan subur sebagai embrio penting bagi dinamika kedermawanan pada masa berikutnya. Solidaritas dan kedermawanan sosial menjadi identitas penting umat Islam. Ini tak terlepas dari ragam tuntunan dan perintah agama untuk saling berbagi dan peduli terhadap sesama. Sedangkan pada masa Khalifah Abu Bakar r.a, ia mendirikan bait al-mal. Donasi diambil dari berbagai macam sumber. Lembaga ini menjadi kiblat bagi para dhuafa. Bahkan menopang sejumlah aktivitas negara, seperti subsidi militer hingga aksi tanggap bencana. Lain lagi di masa Khalifah Umar bin Khatab r.a yang mendirikan lembaga administrasi negara (dawawin) didirikan untuk mendukung optimalisasi bait al-mal. Tiap bayi yang lahir dicatat dan berhak mendapatkan santunan. Bait al-mal dioptimalkan bukan hanya soal pendanaan, tapi juga pemberdayaan ekonomi dan sosial. Jangkauan penerimaan manfaat diperluas hingga luar kota. Bahkan, juga mencakup pemeluk agama lain. Ditambah lagi pada masa Utsman bin Affan r.a dengan meningkatkan subsidi sebanyak satu dirham bagi tiap muslim selama Ramadhan lewat bait al-mal, sedangkan Ali bin Abi Thalib r.a tercatat menyerahkan tanah Yanbu', lembah al-Qura, dan al-Adzaniyah untuk diberdayakan bagi fakir miskin (Nashih Nasrullah: 2014: 15).

Filantropi Islam pada Dinasti Umayah (41-132 H) telah dilakukan berbagai hal, yaitu subsidi rutin bagi para fakir di Hijaz, Irak, melalui kartu khusus, pendirian rumah sakit kusta gratis pertama ada di dunia pada $88 \mathrm{H}$, penggajian bagi pendidik yatim, pendirian panti jompo dan orang-orang hilang, larangan dhuafa dan fakir untuk mengemis, pelunasan hutang bagi mereka yang dililit hutang, subsidi nikah dan pada periode 120-126 H, 10 ribu dirham dianggarkan untuk bencana dan pemerdekaan budak.

Pada Dinasti Abbasiyah (132-656 H) filantropi Islam digunakan untuk distribusi subsidi ke berbagai daerah, jaminan kesehatan bagi rakyat, pendirian lembaga pendidikan bagi yatim piatu dan fakir miskin, perbaikan infra struktur rute bagi jamaah haji, dispensasi waktu bayar pajak. Pada Dinasti Thulun (254$270 \mathrm{H}$ ) filantropi Islam meliputi pendirian dapur umum dengan berbagai menu bagi dhuafa setiap hari dengan biaya operasional sebesar 23 ribu dinar. 
Praktek filantropi ini berlangsung hingga pada Dinasti Ayubiah (569-684 $\mathrm{H})$ dengan melakukan pendirian sekolah sekaligus asrama gratis bagi para sufi dan dhuafa, membangun sekolah-sekolah di Baitul Maqdis, pembangunan rumah singgah bagi peziarah, membangun sekolah kedokteran yang terintegrasi dengan rumah sakit. Dilanjutkan pada masa Turki Usmani (699$1342 \mathrm{H}$ ), pengelolaan filantropi Islam dibuat lebih lengkap lagi. Peraturan untuk membukukan pelaksanaan wakaf, tata cara pengelolaan, sertifikat, mencapai tujuan wakaf dan melembagakan wakaf (Nashih Nastullah: 2014: 15).

\section{B. Filantropi Islam di Indonesia}

Konsep dan nomenklatur ajaran Islam kerap digunakan untuk melegitimasi tradisi filantropi atau penggalangan dana umat untuk kepentingan masyarakat. Seseorang bisa termotivasi karena merasakan perlunya meningkatkan rasa solidaritas yang kuat, yang diistilahkan ukhuwah islamiyah atau persaudaraan Islam dan prinsip al-Ta'awn atau tolong menolong sebagai dasar gerakan Filantropi yang diinterpretasikan untuk gerakan sosial yang berorientasi peningkatan kesejahteraan (Hilman Latief: 2010: xxvii).

Tujuan filantropi Islam adalah menjamin tegaknya keadilan sosial yang merupakan pesan utama ajaran Islam. Filantropi juga bertujuan membersihkan harta dan menyucikan jiwa. Harta harus dibersihkan karena di dalamnya melekat hak orang lain. Dan praktik tersebut akan menyucikan diri dari sifatsifat tamak, kikir dan cinta berlebihan kepada harta (Ahmad Gaus: 2008: 10).

Filantropi telah dipraktekkan sejak awal Islam masuk ke negeri ini, dengan didorong oleh dua institusi keagamaan terpenting yaitu masjid dan pesantren. filantropi telah banyak berkontribusi dalam pengembangan agama Islam dan peningkatan kesejahteraan ummat, bahkan menjadi salah satu sumber pembiayaan perjuangan melawan penjajahan di Indonesia. Namun pengelolaan zakat dan wakaf masih dilakukan secara tradisionalis-individualis. Hal ini terus berlanjut pasca kemerdekaan. Pengelolaan filantropi secara ekonomis-produktif, tetap tidak diperhatikan (Tim Penyusun: 2010: 151).

Sejak tahun 1970-an telah muncul lembaga-lembaga filantropi Islam modern yang berbasis kelembagaan dengan pengelolaan zakat, infak dan sedekah secara professional. Mereka mengelola dana zakat, infak dan sedekah untuk disalurkan bagi usaha-usaha produktif dan berkelanjutan. Bentuknya 
berupa pinjmanan modal usaha bagi pengusaha kecil, pemberian beasiswa pendidikan bagi anak-anak kurang mampu, pendirian balai kesehatan untuk masyarakat tidak mampu dan usaha lain-lain yang menunjang. Mereka memberikan kail, bukan ikan, tujuannya agar pihak penerima bisa diberdayakan secara ekonomi, sehingga nantinya mereka mampu mandiri. Bahkan mereka akan menjadi muqakki atau pihak pemberi dana filantropi bagi kelompok masyarakat lain yang membutuhkan atau belum terberdayakan secara ekonomi. Lembaga-lembaga filantropi tersebut yaitu: Badan Amil Zakat, Infak dan Sedekah (BAZIS) DKI Jakarta, Yayasan Dompet Dhuafa, Pos Keadilan Peduli Umat (PKPU), Yayasan Dana Sosial Al-Falah di Surabaya, Yayasan Daarut Tauhid di Bandung, Yayasan Amil Zakat di Lampung, badan-badan pengumpul zakat milik NU dan Muhamadiyah, masjid-masjid, perusahaanperusahaan, dan lain-lain (Ahmad Gaus: 2008: 8).

Filantropi Islam mengalami mengalami kebangkitan di tangan masyarakat sipil pada tahun 1990-an yang dipelopori antara lain oleh Bamuis BNI yang berdiri tahun 1968, Yayasan Dana Sosial Al Falah pada tahun 1987, dan Dompet Dhuafa Republika pada tahun 1993. Era ini kemudian dikenal menjadi era pengelolaan filantropi Islam secara professional-modern berbasis prinsip-prinsip manajemen dan tata kelola organisasi yang baik. Sejak era inilah kemudian potensi filantropi Islam mulai tergali dengan dampak yang semakin signifikan dan meluas (Tim Penyusun: 2010: 151).

Titik balik terpenting filantropi Islam terjadi pada tahun 1999 yang secara resmi masuk ke dalam ranah hukum positif di Indonesia dengan dikeluarkannya UU No. 38/1999 tentang Pengelolaan Zakat. Berdasarkan UU ini, zakat dapat dikelola baik oleh lembaga amil bentukan pemerintah yaitu Badan Amil Zakat (BAZ) maupun oleh lembaga amil bentukan masyarakat yaitu Lembaga Amil Zakat (LAZ) (Tim Penyusun: 2010: 151).

\section{Filantropi Islam Sebagai Pendidikan Kesalehan Sosial}

Keinginan menjadi seorang filantropi sangat menggiurkan bagi orang yang merindukan keimanan dan keridhoan Sang Pemiliki Kekayaan. Keinginan ini terbuka bagi siapa saja, kecuali yang selalu memelihara kekikiran dan keserakahan (Miftah Farid: 2004: 117). Mengetahui hakikat harta bagi umat Islam sangat penting. Sebab, tanpa memahaminya, manusia justru akan diperbudak oleh harta. Harta yang seharusnya menjaga diri manusia justru membuat 
manusia tidak bisa tidur dan tenang karena harus menjaga hartanya. Salah memiliki harta akan menjadikan harta tersebut bumerang bagi dirinya. Sebaliknya, harta bisa menjadi alat untuk mendapatkan surga, tapi juga bisa menjerumuskannya ke dalam neraka (Didin Hafidhuddin: 2007: 9). Allah SWT berfirman dalam al-Qur'an tentang harta sebagai perhiasan dunia dalam firman-Nya:

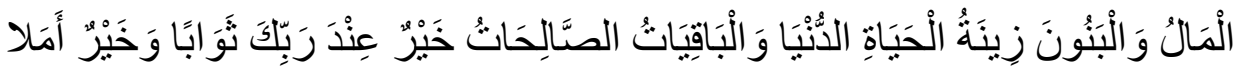

Artinya: "barta dan anak-anak adalah perbiasan kehidupan dunia tetapi amalanamalan yang kekal lagi saleh adalah lebih baik pahalanya di sisi Tubanmu serta lebih baik untuk menjadi harapan.” (Q.S al-Kahfi : 46)

Al-Qur'an mendorong umat Islam untuk mengoptimalkan pelaksanaan zakat, infak, sedekah dan wakaf, baik pengambilan maupun pendistribusiannya. Optimalisasi ziswaf tersebut akan mempunyai pengaruh yang besar terhadap peningkatan dan kesejahteraan dan kegiatan ekonomi (Didin Hafidhuddin: 2007: 30). Sebagaimana tertuang beberapa ayat dalam alQur'an seperti terdapat dalam surat al-Rum ayat 39 dan surat al-Taubah ayat 60 dan aya 103.

Dan sebagaimana Rasulullah SAW menyatakan dalam haditsnya sebagaimana dalam kitab Al-Hadits Al-Mukhtaroh (Al-Dhiya' al-Muqoddasy: t.t: 1765).

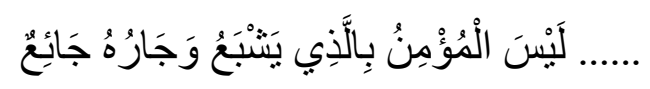

Artinya: "...Tidak beriman orang yang kenyang sementara tetangganya kelaparan"

Ibnu Hazm berkata: "Adalah kewajiban orang-orang kaya di setiap negeri untuk. untuk memenubi kebutuban pokok orang-orang miskin, dan penguasa barus memaksa mereka untuk berbuat demikian sekiranya dana yang terkumpul dari zakat dan fai' tidak mencukupi untuk tujuan ini. Penguasa barus memenubi kebutuhan pokok orang-orang miskin seperti makanan, pakaian musim panas dan dingin, dan perumahan yang tidak. saja akan melindungi mereka dari terik matahari dan hujan, tetapi juga akan memberikan privasi kepada mereka (M. Umer Chapra: 2000: 273). 
Hikmah filantropi Islam bagi yang melakukannya, yaitu integrasi antara kesalehan spiritual dan kesalehan sosial, bukan bagian-bagian yang terpisahpisah (Tim Penyusun: 2000: 12). Para filantropi sebagai penyampai bantuan ekonomi yang tentu saja kaya akan dasar spiritual. Kekayaan atau kesulitan hidup sekalipun dari seorang dermawan tidak membuatnya berhenti menolong orang lain karena dia memandang dirinya sebagai hamba Tuhan yang melayani hamba-hamba-Nya yang lain (Muhammad Gunawan Yasni: 2007: 92). Firman Allah dalam al-Qur'an:

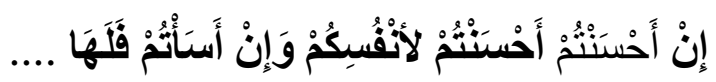

Artinya: "Tika kamu berbuat baik (berarti) kamu berbuat baik bagi dirimu sendiri dan jika kamu berbuat jahat, Maka (kejahatan) itu bagi dirimu sendiri ...” (Q.S. AlIsra 7)

Energi ilabiyah dalam kiprah seorang filantropis terus menyala karena dia senantiasa bersandar kepada Allah. Ali bin Abi Thalib r.a pernah menyampaikan (Muhammad Gunawan Yasni: 2007: 94) :

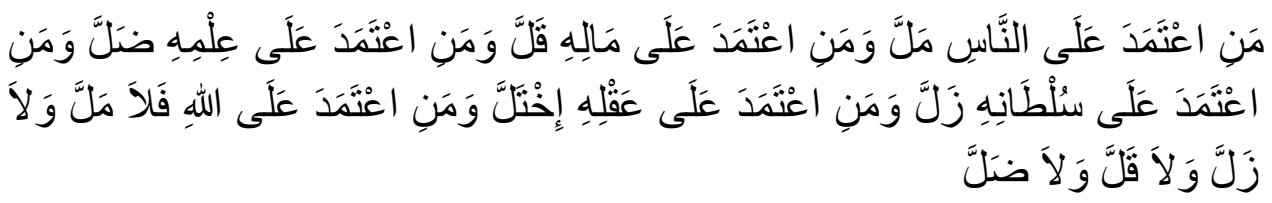

Artinya: "Barangsiapa bersandar pada manusia, ia akan condong, barangsiapa bersandar pada harta, ia akan miskin. Barangsiapa bersandar pada harga diri, ia akan hina. Barangsiapa bersandar pada ilmunya, ia akan tersesat. Barangsiapa bersandar pada pemimpinnya, ia akan tertipu. Namun barangsiapa bersandar pada Allah, sesunggubnya ia tak akan pernah condong, bina, miskin dan sesat."

Substansi yang terkandung dalam ajaran filantropi Islam sangat tampak adanya semangat menegakkan keadilan sosial melalui pendermaan harta untuk kebajikan umum. Walaupun filantropi Islam sebatas amal kebajikan yang bersifat anjuran, tetapi daya dorong untuk menciptakan pemerataan kesejahteraan sangat tinggi. Karena prinsip mendasari ibadah filantropi Islam adalah terciptanya kondisi sosial kemasyarakat yang dibangun di atas kesamaan hak dan kewajiban sebagai makhluk Allah, maka filantropi Islam menduduki peran pemberdayaan masyarakat secara lebih luas untuk meningkatkan taraf hidup dari sekedar mencukupi sehari-hari (Tim Penyusun: 2008: 85-86). 
Dengan filantropi Islam, menunjukkan kepedulian dan tanggung jawab filantropis terhadap kebutuhan masyarakat dan sebagai keuntungan moral bagi filantropi Islam dengan mendapatkan pahala yang akan mengalir terus menerus, walaupun sudah meninggal dunia. Serta memperbanyak aset-aset yang digunakan untuk kepentingan umum yang sesuai dengan ajaran Islam untuk kepentingan kualitas umat seperti kesejahteraan ekonomi, kesehatan, dan Pendidikan (Didin Hafidhuddin: 2003: 123). Tujuan hukum Islam tidak terlepas dari tujuan hidup manusia itu sendiri, yaitu mengabdi kepada Allah. Hukum Islam berfungsi mengatur kehidupan manusia, baik pribadi maupun dalam hubungan kemasyarakatan yang sesuai dengan kehendak Allah, untuk kebahagiaan hidup manusia di dunia dan akhirat (Busthanul Arifin: 1999: 45).

Pahala ibadah sosial merupakan ibadah dalam dimensi sosial dalam rangka pengabdian kepada Allah SWT, seperti filantropi Islam merupakan pahala yang mengalir abadi (Jalaluddin Rakhmat: t.t: 303). Selama ini sering terlihat orang pergi haji berkali-kali karena kelebihan harta, namun banyak yang tidak mempunyai kepedulian social (Siti Nurhayati, dkk: 2005: 47). Orang yang ideal adalah bila orang tersebut saleh dalam dua aspek, yaitu aspek ritual sebagai manifestasi dari perbuatan pribadi seseorang dengan Tuhannya dan aspek sosial yang berupa semua jenis kebajikan yang ditujukan kepada sesama manusia. Untuk mencapai kesalehan ritual, seseorang tidak boleh mengabaikan aspek-aspek sosial (Mohamad Sobary: 2007: 133). Perintah menempatkan kehidupan dunia dan kehidupan akhirat dalam posisi seimbang juga termaktub dalam al-Qur'an dengan firman-Nya:

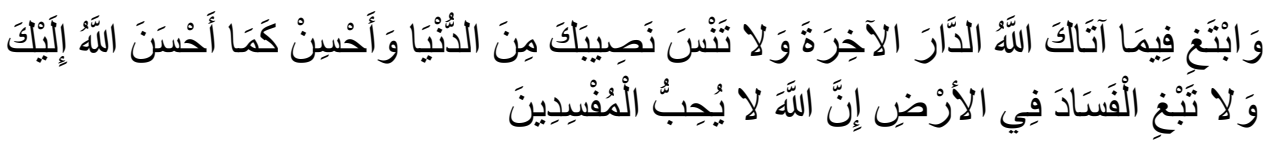

Artinya: "Dan carilah pada apa yang telah dianugerabkan Allah kepadamu (kebahagiaan) negeri akbirat, dan janganlah kamu melupakan bahagianmu dari (kenikmatan) duniawi dan berbuat baiklah (kepada orang lain) sebagaimana Allah telah berbuat baik, kepadamu, dan janganlah kamu berbuat kerusakan di (muka) bumi. Sesunggubnya Allah tidak menyukai orang-orang yang berbuat kerusakan. (Q.S. alQashah : 77)

Dalam sebuah pesan Nabi SAW yang sangat terkenal juga disebutkan (M. Syaiful Bakhri: 2003: vi):

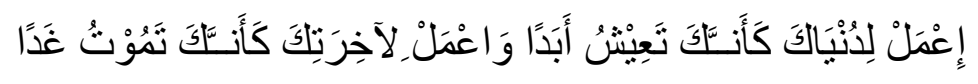

JIEBAR : Journal of Islamic Education: Basic and Applied Research Vol. 01, Nomor 01, April 2020 
Artinya: "Bekerjalah kamu untuk bekal duniamu seakan-akan kamu bidup selama-lamanya, dan beribadablah kamu untuk bekal akbiratmu seakan-akan kamu meninggal besok". (Al-Sakhowi: 2002: 340)

Al-Baihaqy (t.t: 1705) mentakhrij hadits tersebut di atas dalam kitabnya al-Sunan al-Baihaqy dengan redaksi yang lebih sempurna, yaitu:

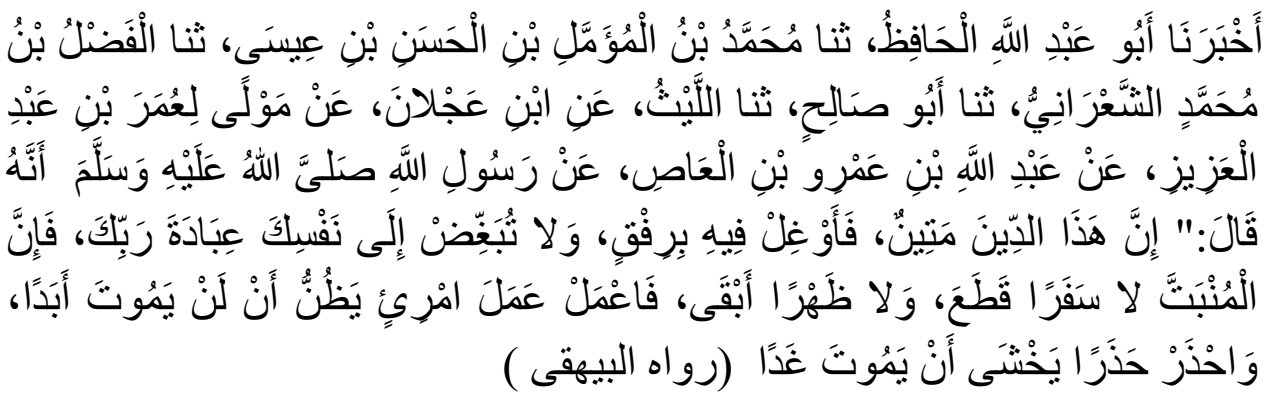

Artinya: "Sesunggubnya agama Islam ini adalah agama yang kokoh dan kuat, maka masuklab ke dalamnya dengan kelemablembutan. Dan janganlah Anda menbenci untuk diri Anda ibadah kepada Allah. Karena sesunggubnya orang yang kekelahan, ia tidak dapat menempuh perjalanan dan tidak pula meninggalkan punggung hewan tunggangannya. Maka beramallah seperti amalnya seseorang yang meyakini babwa ia tidake akan meninggal dunia untuk selamanya! Dan berbati-hatilah seperti kehati-hatiannya seseorang yang khawatir akan meninggal dunia esok hari." (H.R. Baihaki)

Akhirat dan dunia adalah cerminan keseimbangan. Antara akhirat dan dunia mesti saling melengkapi satu sama lain. Menyeimbangkan antara ibadah ritual yang merupakan upaya untuk mengasah ketajaman ruhani dengan ibadah sosial yang merupakan usaha untuk mengasah kepekaan sosial. Pengorbanan yang sangat tinggi tersebut merupakan ibadah sosial yang mesti ditumbuhsuburkan dalam kesadaran dan perilaku keagamaan (M. Syaiful Bakhri: 2003: viii).

Prinsip-prinsip sosial dalam hukum-hukum al-Qur'an lebih memihak pada kemaslahatan dan kebahagiaan masyarakat. Sistem hukuman dalam Islam, misalnya dibangun atas dasar membayar kerusakan. Begitu juga hukum halal dan haram dibangun atas dasar kepentingan umum. Apa yang memihak kepentingan umum maka syara' pun akan menuntut dan memerintahkannya (Muhammad Salman Ghanim: 2000: xx). Motif filantropi Islam didominasi oleh ketaatan, ibadah dan untuk kepentingan hak orang miskin. Tindakan-tindakan keagamaan selalu dimaknai sebagai bentuk manifestasi ketaatan kepada Tuhan, 
tanpa mempertimbangkan falsafah di balik perintah tersebut (Ridwan alMakassary: 2007: 67).

Kehadiran para filantropis dalam jumlah banyak merupakan kebutuhan bagi bangsa Indonesia karena mereka merupakan orang-orang yang senantiasa menyeimbangkan antara keakuannya dengan Tuhan dan keakuannya dengan manusia lain, yaitu keseimbangan yang harmonis antara habl min Allab dan habl min al-nas (Muhammad Gunawan Yasni: 2007: 98).

Pengaruh sosial dari pelaksanaan filantropi Islam akan tampak dari dua sisi, yaitu: Pertama, dari sisi filantropis (orang yang mendermakan hartanya), dengan menunaikan filantropi Islam otomatis membersihkan jiwa dari sifatsifat asosial seperti bakhil, kikir, egoistis, rakus, serta mendorong bersikap sosial yaitu suka berkorban untuk kepentingan umum dan menolong orangorang yang tidak mampu secara ekonomi. Kedua, dari pihak penerima filantropi Islam, bahwa dengan keberadaan filantropi Islam yang bisa diambil manfaatnya untuk memenuhi kebutuhan kehidupannya, akan menghilangkan sifat-sifat buruk yang mungkin terpendam dalam hati seperti dengki, iri, benci, dan rencana jahat terhadap pihak-pihak yang dianggap mampu secara ekonomi dan tidak memperhatikan nasib mereka. Dengan kondisi demikian, dimana antara filantropis dan pihak yang menerima filantropi tercipta saling mendukung dan memahami posisi masing-masing, sehingga stabilitas sosial dan keamanan yang sangat didambakan oleh semua pihak dapat terjaga dengan baik (Tim Penyusun: 2008: 87-88).

Keseimbangan antara kesalehan spiritual dan kesalehan sosial merupakan perintah agama Islam, baik ajaran yang tercantum dalam al-Qur'an, maupun dalam hadits Rasulullah SAW. Dan di antara salah satu kesalehan sosial adalah dengan memberikan filantropi Islam, hal ini sebagai wujud rasa syukur atas karunia rezeki yang diberikan Allah SWT kepada filantropis, juga sebagai rasa empatinya kepada sesama umat Islam dengan harapan dapat meringankan beban hidup mereka. Filantropis yang saleh akan melaksanakan perintah Allah dan Rasul-Nya dengan penuh keikhlasan dan penuh kesadaran bahwa harta dan kekayaan agar tidak terus berputar di sekeliling orang kaya saja, maka dari itu dengan filantropi Islam harta dan kekayaan bisa dinikmati hasilnya oleh fakir, miskin, dhuafa, yatim piatu, dan yang berhak menerimanya untuk meningkatkan kesejahteraan mereka di bidang ekonomi, kesehatan dan pendidikan. 


\section{Potret Filantropi Islam untuk Peningkatan Pendidikan}

Universitas Al-Azhar di Mesir menjadi salah satu contoh Filantropi Islam yang amat luar biasa dengan harta wakafnya dan juga hasil-hasil usaha lainnya. Karenanya, Universitas Al-Azhar menjadi sangat independen dalam pembiayaan pendidikan secara integral dan komprehensif (Azyumardi Azra: t.t: xxvi).

Di Indonesia, filantropi Islam mendapat perhatian besar pemerintah, terbukti dengan lahirnya undang-undang yang mengatur secara khusus wakaf dan zakat. Selain itu, Indonesia juga menyimpan potensi sangat besar untuk mengembangkan dan menginstitusikan filantropi Islam yang profesional. Dari aspek luas dan jumlah, Indonesia mempunyai tanah wakaf yang sangat luas. Menurut data Direktorat Wakaf Bimas Islam Departemen Agama, sampai dengan September 2002, jumlah seluruh tanah wakaf di Indonesia sebanyak 403.845 lokasi dengan 1.566.672.406 M2. 75\% tanah-tanah tersebut telah bersertifikat dan sekitar 10\% memiliki potensi ekonomi tinggi. Besarnya jumlah harta-benda wakaf, khususnya tanah dan bangunan menjadi peluang yang sangat besar bagi pengembangan ekonomi umat dimasa mendatang. Namun, tanah wakaf yang begitu luas ini, sayangnya masih dikelola secara konsumtif dan mayoritas tidak produktif, akibatnya wakaf belum memberikan dampak positif bagi kesejahteraan sosial ekonomi umat. Disamping itu, filantropi Islam juga belum dikembangkan dan dikelola secara optimal dan diinstitusikan secara professional, baik oleh lembaga pendidikan maupun Organisasi Massa Islam (Muhamadiyah, NU, al-Washiliyyah dan lainnya) (M. Ikhsanudin: 2012: 93-94).

Beberapa lembaga di Indonesia, PIRAC dan Dompet Du'afa Republika, telah berhasil mengelola filantropi Islam secara profesional dan mampu mengembangkan potensi filantropi Islam untuk kepentingan pendidikan dan pengembangan kegiatan sosial lainnya. PIRAC dan Dompet Du'afa' Republika mampu mengumpulkan 500 juta rupiah hanya dalam waktu 4 bulan untuk program Layanan Kesehatan Cuma-Cuma (LKC) yang memberikan fasilitas kesehatan permanen untuk masyarakat miskin. Contoh lainnya adalah YPPWPM (Yayasan Pemeliharaan dan Perluasan Wakaf Pondok Modern Gontor), menurut data Wardun per-juli 2005, mempunyai 78,2 Milyar Wakaf tidak Bergerak dan 202.425.844.475,- Wakaf barang bergerak. Beberapa 
institusi dilingkungan lembaga Islam juga terlihat mulai bergeliat untuk mengembangkan wakaf produktif. Universitas Nahdhotul Ulama' (UNU) Solo misalnya membangun ruko (rumah toko) diatas tanah wakaf di daerah Mojosongo Solo. Ruko-ruko tersebut disewakan dan hasilnya digunakan untuk membantu operasional pendidikan dan kesejahteraan civitas akademik UNU (M. Ikhsanudin: 2012: 93-94).

\section{KESIMPULAN}

Filantropi Islam yang diimplementasikan di Indonesia telah didukung oleh perangkat hukum dalam peraturan perundanng-undangan sehingga berbagai pihak yang berkepentingan dapat terus mengembangkan filantropi Islam dengan manajemen modern, transparan dan akuntabel sehingga tidak menimbulkan fitnah terkait korupsi atau manipulasi penggunaan dana filantropi Islam.

Pelaksanaan filantropi Islam sudah berjalan dengan potensinya yang sangat besar karena jumlah penduduk di Indonesia yang beragama Islam menduduki posisi terbanyak. Dengan demikian sangat wajar jika masa depan filantropi Islam akan lebih maju karena kesadaran yang dibangun oleh pendidikan filantropi Islam dan sosialisasinya dilakukan oleh institusi pendidikan, pemerintah dan lembaga swadaya secara sinergis sehingga semakin membuat umat Islam di Indonesia terus menerus partisipasi untuk menyalurkan dana filantropinya. Dukungan politik dan pemerintah disertai dorongan yang kuat dari umat Islam terhadap filantropi Islam membuka peluang yang seluas-luasnya terhadap kesejahteraan masyarakat.

Kesalehan spiritual dan kesalehan sosial perlu dibentuk sejak dini mungkin melalui pendidikan dan pengajaran yang dilakukan di sekolah dasar dan menengah. Kedua bentuk kesalehan tersebut seperti dua mata uang yang tidak bisa dipisahkan satu sama lain, sehingga orang yang saleh secara spiritual menjadi lebih membumi dan berpengaruh nyata terhadap lingkungan sekitarnya.

\section{REFERENSI}

Ahmad Gaus, 2008. Filantropi dalam Masyarakat Islam, Jakarta: Elek Media Komputindo 
Al-Sakhowi, 2002. al-Maqaashid al-Hasanah Fïma Isytahara 'Ala al-Alsinah, Beirut: Dar al-Kutub al-'Araby

Al-Baihaqy, t.t. al-Sunan al-Kubro al-Baihaqy, Makkah al-Mukarromah: Maktabah Dar al-Baz

Al-Dhiya' al-Muqoddasy, t.t. al-Ahadits al-Mukhtaroh, Saudi: t.p.

Azyumardi Azra, t.t. Berderma Untuk Semua, Jakarta: Mizan

Busthanul Arifin, 1999. Pelembagaan Hukum Islam di Indonesia: Akar Sejarah, Hambatan dan Implementasinya, Jakarta: Gema Insani Press

Didin Hafidhuddin, 2007. Agar Harta Berkah dan Bertambah, Jakarta: Gema Insani Press

Didin Hafidhuddin, 2003. Islam Aplikatif, Jakarta: Gema Insani Press

Hilman Latief, 2010. Melayani Umat: Filantropi Islam dan Ideologi Kesejabteraan Kaum Modernis, (Jakarta: Gramedia Pustaka Utama

Jalaluddin Rakhmat, t.t. Membuka Tirai Kegaiban: Renungan-Renungan Sufistik, Jakarta: Mizan

M. Ikhsanudin, 2012. Optimalisasi Wakaf Produktif Bagi Lembaga Pendidikan Dan Ormas Islam Di Indonesia, Jurnal Mukaddimah, Vol. 18, No. 1. Yogyakarta: Sekolah Tinggi Ilmu al-Qur'an An-Nur

M. Syaiful Bakhri, 2003. Oase Spiritual: Hikmah Dalam Ujaran dan Kisah, Jakarta: Erlangga

M. Umer Chapra, 2003. Islam dan Tantangan Ekonomi, Jakarta: Gema Insani Press

Miftah Farid, dkk., 2004. Adakah Allah Selalu di Hatimu, Jakarta: Republika

Muhammad Gunawan Yasni, 2007. Ekonomi Sufistik: Adil dan Membahagiakan, Bandung: Mizan Pustaka

Muhammad Salman Ghanim, 2000. Kritik Ortodoksi Tafsir Ayat Ibadah, Politik, dan Feminisme, Yogyakarta: LKiS

Mohamad Sobary, 2007. Kesalehan Sosial, Cet. I. Yogyakarta: LKiS

Nashih Nasrullah, 2014. Filantropi Penopang Solidaritas, terbit Ahad 16 Maret 2014. Jakarta: Harian Republika

Ridwan al-Makassary, 2007. Transparansi dan Akuntabilitas Filantropi Islam Untuk Keadilan Sosial: Beberapa Observasi, Jurnal Galang Vol. 2, No. 2, Depok: Pirac

Siti Nurhayati, dkk., 2005. Pahala Itu Mudah, Jakarta: Penerbit Republika 
Tim Pusat Bahasa, 2008. Kamus Bahasa Indonesia, Jakarta: Departemen Pendidikan Nasional

Tim Penyusun, 2010. Indonesia Economis Outlook 2010: Makro Ekonomi, Demografi, Ekonomi Syariah, Jakarta: Grasindo

Tim Penyusun Buku, 2008. Paradigma Baru Wakaf di Indonesia, Jakarta: Direktorat Pemberdayaan Wakaf 